\title{
IF THIS IS MY BODY ... : A DEFENCE OF THE DOCTRINE OF DOING AND ALLOWING
}

BY

FIONA WOOLLARD

\begin{abstract}
I defend the Doctrine of Doing and Allowing: the claim that doing harm is harder to justify than merely allowing harm. A thing does not genuinely belong to a person unless he has special authority over it. The Doctrine of Doing and Allowing protects us against harmful imposition - against the actions or needs of another intruding on what is ours. This protection is necessary for something to genuinely belong to a person. The opponent of the Doctrine must claim that nothing genuinely belongs to a person, even his own body.
\end{abstract}

In each of the following cases, Bob has been bitten by a poisonous snake and will die without immediate hospital treatment.

Non-Interpose: A boulder is rolling towards Victor who is trapped and cannot be freed without special equipment. Bob could drive his car into the boulder's path, bringing it to a halt. If he does so he will not reach the hospital in time. He does not interpose the car. The boulder hits and kills Victor.

Push: The boulder is in the middle of the road, blocking Bob's only route to the hospital. Bob pushes the boulder. The boulder rolls down the slope, hits and kills Victor.

Most people see a striking moral difference between these two cases. It seems perfectly permissible for Bob to refuse to interpose the car in NonInterpose, but wrong for Bob to push the boulder towards Victor in Push, The obvious explanation is that Bob does harm to Victor in Push, whereas he merely allows harm to Victor in Non-Interpose. Many people think

Pacific Philosophical Quarterly 94 (2013) 315-341 DOI: 10.1111/papq.12002

(C) 2013 The Author

Pacific Philosophical Quarterly (C) 2013 John Wiley \& Sons Ltd \& University of Southern California. 
there is a morally significant difference between doing harm and merely allowing harm. Doing harm is harder to justify than merely allowing harm. This is known as the Doctrine of Doing and Allowing. Commonsense morality seems to endorse this doctrine. Indeed, rejecting it would apparently lead to radical revision of our understanding of our moral obligations. Yet many philosophers have argued against it. ${ }^{1}$

I defend the Doctrine of Doing and Allowing by arguing that this Doctrine is necessary if anything is to genuinely belong to a person, even that person's body. This is not a new idea. Warren Quinn argues that the constraint against doing harm is necessary to recognise the fact that the potential victim's body and mind belong to him. Quinn claims that without the constraint against doing harm a person's body may be damaged whenever this is necessary to prevent greater harm occurring to others. His interests count for no more than anyone else's in determining what may be done to his body. His body is treated as common property rather than as genuinely belonging to him. ${ }^{2}$

Like Quinn, I think that a constraint against doing harm is needed if a person's body is to genuinely belong to him. To say that something belongs to a person is to say that it is his in a way that gives him a privileged status with respect to it. His needs and desires should count for more than the needs and desires of others in determining what may be done to the resource. Without this privileged status, we do not have genuine belonging but mere association. If other people are just as free to drive a car as I am, if they are permitted take it away or take it apart whenever they need to, it is not really my car. It is a commonly-owned car. The same holds for my body. If this body is to genuinely belong to me, rather than being a commonly-owned resource, I need normative protection that gives me a privileged status with respect to this body. By normative protection, I mean something like a rule that it is prima facie impermissible for others to behave in certain ways without my consent. Something can still genuinely belong to me even if others do in fact take it from me or if others are permitted to take it from me in certain situations. This just means that my authority over what belongs to me has been infringed or over-ridden. But if others are permitted to take something from me whenever this is for the best, if there is no normative restriction that counts my needs and desires for more than theirs, then it does not genuinely belong to me in the first place.

Quinn's defence of the Doctrine of Doing and Allowing is importantly incomplete. As Frances Howard-Snyder comments: 'Quinn's is a funny sort of defense of negative rights. Unless I'm missing something, it doesn't pick out any special feature of negative rights that makes them specially worth respecting. ${ }^{3}$ Quinn argues convincingly that a system without constraints, in which what is to be done is decided solely on the basis of interests, does not adequately recognise that a person's body belongs to 
him. But he has not shown why we should have constraints against doing harm. For all Quinn has said, any other set of constraints would do just as well. He does argue that a system with strong constraints against allowing harm and weaker constraints against doing harm would be incoherent. ${ }^{4}$ But he fails to address the key question of why the constraints should be built around the doing/allowing distinction at all. ${ }^{5}$ Similar objections apply to other attempts to defend the Doctrine of Doing and Allowing by arguing that it is necessary for our bodies or other resources to belong to us. $^{6}$

I aim to fill these crucial gaps by explaining the connection between the Doctrine of Doing and Allowing and the conditions for genuine belonging. I argue that the Doctrine of Doing and Allowing is best understood as a principle that protects us against harmful imposition against the actions or needs of another intruding on what is properly ours. This protection is necessary for something to genuinely belong to a person.

My defence requires analysis of the distinction between doing and allowing. Until we understand the nature of the distinction, we will be unable to see how it connects to the conditions for genuinely belonging. In Section 1, I will provide such an analysis. In Section 2, I will introduce the idea of imposition and show that my account of the distinction between doing and allowing gives rise to a way of understanding imposition that makes sense of the thought that some ways of affecting, or placing demands upon, others involve intruding into their proper sphere. This reveals that the Doctrine of Doing and Allowing can be understood as a principle that protects us from harmful imposition. In Section 3, I explore the conditions for genuine belonging in detail and argue that the protection against imposition provided by the Doctrine of Doing and Allowing is necessary if anything is to genuinely belong to us.

In the remainder of the article I deal with various objections that might be raised against my argument. In Section 4, I discuss exceptions and limits to the protection against imposition, responding to objections that the authority we have over what belongs to us is best understood as a loose bundle of rights. In Section 5, I consider objections to my use of the notion of belonging. I explain why our bodies and other resources belong to us rather than belong*ing to us (a relationship that is like belonging but neutral between doing and allowing). I argue that objections that a person does not own his body do not undermine my claim that each person's body belongs to him. I show how my account can deal with differences between doing and allowing harm to entities incapable of having belongings. In Section 6, I defend my use of the distinction between positive and negative facts. In Section 7, I explain how my analysis can avoid an important counter-example. 


\section{The doinglallowing distinction}

To analyse the distinction between doing and allowing, I will use the Push and Non-Interpose cases described earlier and two additional cases:

Drive-Away (BC): The boulder is rolling towards Victor. Bob's car is parked in the boulder's path. Anxious to get to hospital, Bob drives it out of the boulder's path. The boulder hits Victor.

Drive-Away (VC): Victor's car is parked in the boulder's path. Bob drives the car out of the boulder's path. The boulder hits Victor.

In this section, I will take it as data that Push is a case of doing harm, Non-Interpose, a case of allowing harm, Drive-Away (BC), a case of allowing harm and Drive-Away (VC), a case of doing harm. Push and Non-Interpose are non-controversial. In Drive-Away (BC), Bob prevents his own car from preventing the harm to Victor. It makes sense to see this as a mere refusal to aid. In Drive-Away (VC), Bob prevents Victor's own car from protecting Victor from the boulder. It seems very odd to deny that this counts as doing harm to Victor. Nonetheless, some people may not initially agree with my classifications of these cases. The article as a whole represents a defence of my classifications. In the article as a whole, I show that my use of the terms 'doing' and 'allowing' picks out a distinction with the kind of moral significance typically attributed to the doing/ allowing distinction.

Bob merely allows harm in Drive-Away (BC) even though he is relevant to the harm through an action. There is another distinction in this area which is often confused with the doing/allowing distinction. Sometimes harm occurs because an agent has performed an action - because he pushed a rock or moved a car. Sometimes it occurs because he has not performed an action - because he failed to push a rock or refrained from moving a car. I refer to this alternative distinction as the action/inaction distinction. It is easy to confuse these two distinctions because we speak of performing an action as doing something. Nonetheless, the distinctions are not the same. This is brought out clearly in Jeff McMahan's Theft case:

Theft: Due to a medical condition, Other will become disfigured unless he has an expensive operation within the next week. Other seizes wealthy Agent's wallet, which contains enough cash to pay for the operation. Agent chases Other and retrieves his wallet. Other becomes disfigured. ${ }^{7}$

In Theft, Agent is relevant to Other's disfigurement through an action. Yet he merely allows Other to become disfigured. Common-sense morality treats both the action/inaction distinction and the doing/allowing distinc- 
tion as morally relevant. The focus of this article is the doing/allowing distinction not the action/inaction distinction. Bearing this in mind may assuage some initial doubts about my classification of the Drive-Away cases.

My account of the doing/allowing distinction starts with an observation by Philippa Foot. Foot comments: 'we think of particular effects as the result of particular sequences, as when a certain fatal sequence leads to someone's death. This idea is implied in coroner's verdicts telling us what someone died of . . . ${ }^{8}$ For example, in Push, we say that Victor died because Bob pushed the boulder; the boulder rolled down the hill and hit Victor.

When we pick out the sequence leading to an outcome, we draw a distinction among the relevant facts. Some relevant facts are seen as part of the sequence leading to harm. Others are seen merely as background conditions, relevant to, but not part of, the sequence. In Push, the fact that the boulder rolled down the hill is part of the sequence leading to Victor's death, while the fact that there was no wall to protect Victor from the boulder is merely a relevant background condition. I suggest that an agent does harm if and only if a fact about his behaviour is part of the sequence leading to that harm. An agent merely allows harm if and only if all relevant facts about his behaviour are merely background conditions. ${ }^{9}$

Some facts are by nature suitable to be part of a sequence. I will refer to these as 'substantial facts'. Other facts are, normally, merely background conditions. I will refer to these as 'non-substantial facts'. Reusing the examples above, the fact that a boulder is rolling down a hill is the type of fact that is suited to be part of a sequence, the fact that there is no wall in the boulder's path is normally merely a background condition. Later, I shall say more about what makes a fact substantial and when a nonsubstantial fact might count as part of a sequence. For the moment, I will focus on laying out the role of this distinction in my account of the doing/allowing distinction.

If the relevant fact about an agent's behaviour is non-substantial, this fact will count as a mere background condition. If this is the only fact about his behaviour that is relevant, he will count as merely allowing harm. This is what we see in Non-Interpose. Bob is only relevant to Victor's death through the fact that he did not move the car into the boulder's path. The fact that an agent failed to move a car is a nonsubstantial fact. This fact is not part of the sequence leading to Victor's death. Bob counts as merely allowing harm.

However, an agent might count as merely allowing harm even if the relevant fact about his behaviour is substantial. In Drive-Away (BC), the fact that Bob moved the car is relevant to Victor's death. This is a substantial fact. It is suitable to be part of a sequence. Indeed it is part of the sequence leading to Bob's survival. Yet Bob counts as merely allowing harm. 
On reflection, this is not surprising. Not every relevant substantial fact is part of the sequence. We need to look at the facts through which the agent is relevant to the harm. When a fact about an agent is relevant to a given upshot, this is usually because it is relevant to certain other facts that are themselves relevant to the upshot. I say that a relevant fact, F, is relevant solely through another fact, G, when the following counterfactual holds: if $\mathrm{G}$ were not relevant to the upshot, $\mathrm{F}$ would not be relevant either. In Drive-Away (BC), the fact that Bob moved the car is only relevant to Victor's death because it meant that the car was not in the boulder's path and because the fact that the car was not in the boulder's path is relevant to Victor's death. Suppose that it were not relevant that the car was not in the boulder's path. Suppose the boulder was too big to be stopped by the car. Then Bob's behaviour would not be relevant either. The fact that Bob drove the car is relevant to Victor's death solely through the fact that the car was not in the boulder's path.

The fact that the car was not in the boulder's path is a non-substantial fact. The absence of a barrier will (normally) count as a mere condition rather than part of the sequence leading to harm. If an agent's behaviour is relevant to the harm solely through a background condition, then his behaviour cannot be part of the sequence. Anything that is relevant to a harm solely through a background condition to the harmful sequence's occurrence must itself be merely a background condition. This explains why Bob counts as merely allowing harm in Drive-Away (BC). In general, a relevant fact about an agent's behaviour will, normally, count as merely a background condition to the harmful sequence if it is either non-substantial itself or relevant to the harm solely through some non-substantial fact.

To be substantial, a fact must have some feature that makes it more than simply a background condition. There are several different ways a fact can be substantial. In this article I shall focus on only the most prominent one. We see some facts as positive, while others seem negative. 'It is raining' seems positive, while 'it is not raining' seems negative. Positive facts tell us that something is the case, while negative facts tell us that something is not the case. Positive facts are substantial: the fact that something is the case is the sort of fact that is suitable to be part of a causal chain; the fact that something is not the case is simply a background condition - unless it has some other feature that makes it count as a substantial fact.

I deliberately say that a non-substantial fact will normally be merely a background condition. Sometimes a non-substantial fact will be part of a harmful sequence. Facts about the absence of barriers are negative, thus non-substantial. However, not all removals of barriers count as merely allowing harm. In Drive-Away (VC), when Bob removes Victor's car from the boulder's path, the removal of a barrier counts as doing harm. There are many similar examples. If I remove Fred's parachute before a jump, I count as doing harm although I have simply removed a barrier to harm. 
Certain features can make a fact relatively substantial so that it is suitable to be part of a harmful sequence. In the examples above, the absence of the car and the absence of the parachute both count as part of the sequence leading to harm - although they are both non-substantial facts. The facts are substantial relative to the upshots in question. When this occurs there will always be some feature of the situation that makes the non-substantial fact substantial relative to the upshot. While substantial facts count as part of the sequence for any upshot to which they are appropriately relevant, a relatively substantial fact is only part of the sequence for some particular upshot. As the absence of the car is only relatively substantial, it is part of the sequence leading to Victor's death, but merely a background condition for other sequences. For example, plants might grow where the car once stood, which would not have grown had the car remained where it was and blocked the sun from that patch of ground. The absence of the car is merely a background condition for the sequences leading to the plants' growth.

The locus classicus for discussion of removing barriers to harm is Jeff McMahan's paper 'Killing, Letting Die, and Withdrawing Aid'. According to McMahan, whether removal of a barrier counts as doing harm or merely allowing harm turns on who provided the barrier and whether the barrier requires continued contributions from the agent. ${ }^{10}$ When an agent removes a barrier that he has provided and that requires further contributions from him, then he is effectively discontinuing an effort to aid. $\mathrm{He}$ merely allows harm. In contrast, when the agent removes a barrier that does not require further contributions from him, he is not merely discontinuing aid. He does harm.

McMahan gives us two conditions under which a barrier requires further contributions from the agent: (1) the barrier is not yet selfsustaining (the agent must do something to keep the barrier in place); (2) the barrier is not yet operative. The first condition is obvious - an agent is certainly in the process of providing aid if he must do something to keep the aid effective. The second condition is given to deal with cases in which the agent does not need to do anything to maintain the barrier to harm, but the withdrawal of the barrier to harm still seems like a mere allowing. For example:

Impoverished Village: Due to a misunderstanding, your accountant is about to sign away $10 \%$ of your income to save the lives of people in a remote impoverished village. You tell him not to do it. ${ }^{11}$

McMahan explains our classification of Impoverished Village by noting that the aid is not yet operative. The villagers count as depending on 'further' aid from the agent. Withdrawal of the barrier counts as merely discontinuing aid. 
However, we can construct versions of Impoverished Village in which the aid is both self-sustaining and apparently operative, but the agent still counts as merely allowing harm. Suppose the agent's money is sitting in a bank account that is set up so that the interest goes to the village each month. The villagers have been using this income to feed themselves for over a year. The agent does not need to do anything to keep the aid going and his aid seems to be operative. Nonetheless, as long as the money belongs to the agent, removing the money is merely allowing harm. ${ }^{12}$ The key question is not whether the barrier is self-sustaining or operative, but whether it requires the continued use of resources belonging to the agent, either his body or some other resource.

This suggestion fits in with the most plausible way of understanding what it is for an agent to provide a barrier. In Impoverished Village, the agent did not do anything to set the barrier up. It is the accountant who is preparing to sign the money away. The agent does not count as providing the barrier on the basis of his actions but because the money belongs to him. If we are to make sense of the fact that Impoverished Village is a clear case of merely allowing harm, we must count the agent as providing the money. We can only do this if we admit that an agent can provide a barrier, not because he has done something to put it in place, but because it consists of resources that belong to him. Once we accept this, what reason could we have for rejecting the claim that a barrier can count as requiring continued contributions from an agent because it requires the continued use of resources that belong to him?

In Impoverished Village, when the money belongs to the agent, taking it away is merely allowing harm. In contrast, if the money belonged to the villagers, removing the money would count as doing harm. In the DriveAway cases, removing the car is merely allowing harm in $\mathrm{BC}$, where the car belongs to Bob, but doing harm in VC, where the car belongs to Victor. I suggest that non-substantial facts about the agent's behaviour or resources are mere background conditions. Such facts simply represent the absence of something of the agent's that could have prevented the harmful sequence. Bringing about such facts is merely allowing harm. However, if a barrier belongs to the victim, the fact that that barrier is absent is not simply a background condition for the harmful sequence. Protection which the victim had provided for himself is no longer there. The relationship between the victim and the resource makes the normally nonsubstantial fact more than a mere background condition for the sequence leading to harm to that victim. It is relatively substantial and therefore suitable to be part of the harmful sequence. Bringing about this fact is doing harm.

My focus is the doing/allowing distinction. I am interested in what makes an agent count as relevant to harm in a doing way rather than an allowing way. An agent may need to meet several other conditions for us 
to say that he has done or allowed harm. We will not typically say that an agent has done or allowed harm if the sequence leading to harm depended on a series of unlikely intervening coincidences or ran wholly through another's independent will. ${ }^{13}$ The nature and moral relevance of these conditions is beyond the scope of this article. I will say that an agent's behaviour is 'suitably relevant' if he meets this set of additional conditions, leaving it open which conditions are included in this idea and whether they should be accorded moral relevance.

In summary:

An agent counts as doing (bringing about) a harm if and only if a fact about his behaviour is suitably relevant and part of the sequence leading to harm.

An agent counts as merely allowing a harm if and only if a fact about his behaviour is suitably relevant to the harm but not part of the sequence leading to harm.

A suitably relevant fact about an agent's behaviour is part of the sequence leading to a harm if and only if:

(a) The fact is itself substantial or relatively substantial and

(b) The fact is not solely relevant to the harm through a fact that is neither substantial nor relatively substantial.

Non-substantial facts about resources belonging to the victim are relatively substantial. Non-substantial facts about resources belonging to the agent are not relatively substantial. ${ }^{14}$

On my analysis, whether an agent counts as doing harm or merely allowing harm depends on facts about what belongs to whom. We have a good intuitive grasp on what it is for a resource to belong to a person. Roughly speaking, for a resource to belong to a person is for it to be allocated to his use. This allocation is not on the basis of need but on the basis of some need-independent relationship between the resource and the person. In the Impoverished Village example, we are told that the money that is about to go to the villagers is ' $10 \%$ of your income'. We picture the money going into your bank account on payday. We recognise this money as belonging to you. Similarly, when told about 'Bob's car', we imagine Bob taking his savings to the car dealership and receiving in return a shiny Ford and bundle of ownership papers. Later I will explore the notion of belonging in detail. For now, I appeal to our intuitive recognition of the appropriate relationships.

Some may find my appeal to facts about belongings objectionable. The doing/allowing distinction seems, at first glance, a purely descriptive distinction that should not depend on such normative criteria. These concerns are understandable but misplaced. As the Drive-Away cases show, whether we count a person as doing or merely allowing does depend on 
facts about what belongs to whom. Cases of this type are too numerous to dismiss as the result of our classification being distorted by normative factors that are external to the 'real' doing/allowing distinction. Impoverished Village is a clear case of merely allowing harm, but if we change the normative facts so that the money belongs to the villagers instead of the agent, removing the money counts as doing harm. The same is true of McMahan's Theft case, described earlier and of many similar cases.

Moreover, this dependence on normative facts is entirely appropriate. As I will argue below, the distinction between doing and allowing is at heart a distinction between behaviour that intrudes on another and behaviour that does not so intrude. Whether you are intruding on me will depend upon whether the objects that you affect belong to me. The doing/ allowing distinction should be sensitive to claims about belongings.

\section{Imposing on another and the doinglallowing distinction}

Frances Kamm notes the following difference between cases of killing and cases of letting die:

If the same efforts had to be made to avoid killing as have to be made in order to save a life, they would be made to prevent the killer from imposing first on an innocent person. In contrast, the efforts made in saving would, in a sense, involve the innocent bystander being imposed on first for the dying person. ${ }^{15}$

Kamm illustrates this with two examples. In the first, you swerve your car into a tree to avoid driving into a pedestrian. Kamm claims that in this case you take action to avoid imposing first on the potential victim. In the second, you save someone's life by swerving into a tree. Kamm claims that in this case you are imposed upon first for the sake of the potential victim. ${ }^{16}$

Kamm's observation taps into a familiar idea. We think that sometimes what we do or what we demand intrudes into another's proper sphere. We call this kind of intrusion 'an imposition'. As Kamm notes, hitting the pedestrian and requiring the driver to save the pedestrian involve different types of imposition..$^{17}$ If the driver hits the pedestrian, he intrudes upon the pedestrian with his behaviour, causing adverse effects to the pedestrian's body. I call this type of imposition causal imposition. If the driver were required to save the pedestrian, the pedestrian's needs would intrude upon the driver, making demands upon him. I call this type of imposition normative imposition. Doing harm involves causal imposition on the victim; constraints against allowing harm involve normative imposition on the agent.

Both types of imposition require further analysis. Why do we think that the pedestrian is imposed on by the driver when he is hit by the car but not 
when the driver lets the tree fall on him? Why do requirements to save seem to intrude while requirements not to harm do not? My account of the doing/allowing distinction suggests an understanding of imposition that sheds light on the idea that imposition involves intrusion into the proper sphere of another and explains the connections between doing/allowing and imposing.

If an agent allows harm, he only directly affects things that belong to him. Although things happen to others that would not have happened if he had acted differently, his behaviour is not part of the sequence leading to these effects. Any potential sequence of substantial facts leading from the agent's behaviour is broken by a non-substantial fact about his behaviour or his resources. The sequences of substantial facts stop before they reach out beyond his sphere of belonging. In contrast, when an agent does harm, he is part of the sequence leading to harm to the victim. There is a sequence of substantial facts leading from his behaviour to an effect on something that belongs to the victim. We see his behaviour as reaching into the sphere of the victim. Unless this effect is mediated by, for example running through another person's independent will or depending on a series of unforeseeable coincidences, the agent's behaviour will be an imposition.

This suggests the following account of causal imposition:

A victim is causally imposed on by an agent if and only if the agent's behaviour is suitably relevant to some effect on what belongs to the victim and there is a sequence of substantial facts from the agent's action leading to this effect.

My account of the doing/allowing distinction also suggests a natural understanding of normative imposition. On my account, when an agent allows harm he is relevant to the harm through a non-substantial fact about his behaviour or his resources. Constraints against allowing harm forbid him from being relevant to harm through a non-substantial fact about his behaviour or his resources. They require him to ensure the contrary substantial fact holds instead. Ensuring that a substantial fact about one's behaviour or resources is true for the sake of another person amounts to putting one's belongings at another's use. It makes sense to see this as a normative imposition: an intrusion of the needs of others into one's sphere.

This gives us the following account of normative imposition:

An agent is normatively imposed on by a victim if and only if he is required to make some substantial fact about his body or his resources hold for the sake of another. 
If we understand imposition in this way, then the doing/allowing distinction matches a difference in the structure of imposition. Doing harm involves a sequence of substantial facts leading from the agent's behaviour to an effect on something that belongs to the victim; allowing harm does not involve such a sequence. Constraints against allowing harm forbid the agent from being relevant to harm through a non-substantial fact about his behaviour or resources. They require him to make the contrary substantial fact hold instead. Constraints against doing harm do not require the agent to make a substantial fact about his behaviour or his resources hold. Thus, doing harm as such causally imposes on the victim; when allowing harm the agent does not as such causally impose on the victim. Additionally, constraints against allowing harm as such normatively impose upon the agent; constraints against doing harm do not as such normatively impose upon the agent. ${ }^{18}$

When we see the Doctrine of Doing and Allowing in this light, it is revealed as a principle protecting us from harmful imposition. According to the Doctrine of Doing and Allowing, doing harm is ordinarily forbidden even if all alternatives are costly, whereas allowing harm is ordinarily permissible if all alternatives are costly. When an agent does harm, he (causally) imposes on his victim. When an agent is forbidden from allowing harm he is (normatively) imposed on by the potential victim. The Doctrine of Doing and Allowing protects us against both harmful causal imposition and harmful normative imposition: agents are not permitted to causally impose on patients in a harmful way (doing harm is forbidden); patients cannot normatively impose upon agents in a harmful way (allowing harm is permissible).

\section{Belonging and constraints against imposition}

Earlier, I noted that we have a good intuitive grasp of what it is for something to belong to a person. I will now give an account of belonging. With the above observations about doing and allowing and imposing, this account of belonging will enable me to fill the crucial gap in ownershipbased defences of the Doctrine of Doing and Allowing. I will show why it is the Doctrine of Doing and Allowing, rather than some alternative set of constraints, that is necessary for bodies and other resources to genuinely belong to persons. As I will argue, for anything to genuinely belong to a person requires the protection against imposition offered by the Doctrine of Doing and Allowing.

To say that a person legally owns $\mathrm{O}$ is to say that (a) he stands in a certain relationship to it (he possesses the title deeds; it is in his bank account etc.) and (b) that according to the appropriate legal system, standing in this relationship to $\mathrm{O}$ means that $\mathrm{O}$ counts as his in a way that has 
a familiar legal significance. It has a cluster of implications for what the person and others may legally do with respect to O. If I own a car, I am legally entitled to drive it or to give others permission to drive it. I can make changes to its appearance. Others are not legally permitted to do these things without my consent. ${ }^{19}$ Like claims about legal ownership, the claim that a resource belongs to a person asserts a relationship between the person and the resource with a cluster of normative implications. However, there are important differences.

First, I am interested in belonging as a moral concept not a legal concept. In working out whether a given resource belongs to a person for the purposes of the doing/allowing distinction, we may need to look beyond the law. The relevant normative implication will concern what is morally permissible not what is legally permissible.

Second, 'belonging' is a thinner and more basic notion than ownership. A resource can belong to a person even if most of the rights and privileges associated with ownership are not present. If Bob has rented or borrowed a car from a neutral third party, this car counts as belonging to Bob for the purposes of the doing/allowing distinction. Yet, he does not own the car. It only belongs to him for a set period of time. He is not permitted to sell it and may not be permitted to allow others to drive it; he may be required to return it in a certain state. Belonging does not include the indefinite term nor the rights to transfer title or to alter or destroy the resource that accompany full ownership. I think of belonging as the core concept we use when dividing the world up into what is mine and what is yours. To say that a resource belongs to a person is to say that it is his in a way that gives him a privileged status over the current use of that resource. This privileged status gives him a prima facie authority to make decisions over what happens to those resources based on his own interests and desires. ${ }^{20}$

What exactly does this authority over the object involve? Here the literature on legal ownership is useful. Two key rights of ownership identified by this literature are the right to possess (the right to have exclusive physical control of a thing) ${ }^{21}$ and the right to use (the right to the personal use and enjoyment of the thing owned). ${ }^{22}$ A.M. Honoré describes the right to possess as 'the foundation on which the whole superstructure of ownership rests'. ${ }^{23}$ I suggest that the two rights are also a key part of the more basic notion of belonging and that they require the protection against imposition provided by the Doctrine of Doing and Allowing.

According to Honoré, the right to possess has two aspects: the claim to be put in exclusive control of a thing and the right to remain in control, 'viz. the claim that other should not without permission, interfere'. ${ }^{24}$ Such protection against interference is vital if a resource is to genuinely belong to a person. If others are permitted to use, move, alter or destroy a resource whenever they need to, it is not really mine in the sense we are considering. It might be associated with me in some way, but it is not mine 
in the normative sense. For something to genuinely belong to me in this sense, I must have (prima facie) authority to prevent others from affecting the resource. It must, to a certain extent, be up to me to decide what happens to that resource.

It is only to a certain extent that what happens to the resource must be up to the person. My authority over my body is not infringed if I get soaked by a sudden rainstorm even if you are standing beside me with a spare umbrella. Others are not required to maintain the things that belong to us. Instead, we need protection from the effects of others' behaviour. If something genuinely belongs to me, if it is my car, or my body, then others are (prima facie) forbidden from damaging it or changing its condition without my permission, but are not required to protect it. This is implicit in Honoré's discussion: he speaks of protection against non-interference rather than general protection against unwanted alterations.

This makes sense. When something belongs to me, I have authority over that thing. I do not have authority over the realm of nature or the resources of others. My authority over what belongs to me involves only a power of exclusion - the authority to forbid the activity of others from intruding into the sphere of things that belong to me. If something genuinely belongs to me it should be protected against just the kind of effect we see in causal imposition: it should be prima facie impermissible for others to causally impose on me with respect to that thing without my consent.

Some may find the claim that I must have protection against all causal imposition implausible. There are many ways in which we permissibly affect what belongs to others in everyday life. This does not undermine their authority over what belongs to them. As I shall argue in the next section, I do not see these permissible impositions as counterexamples to my claim. I claim only that we have prima facie protection against imposition.

Protection against unwanted effects alone is not enough for a person's resources to genuinely belong to him. Genuine belonging also requires the right to use identified by Honoré: the right to the use or enjoyment of the resource. ${ }^{25}$ Something does not truly belong to a person if he is required to use it in a particular way or required to let others use it whenever doing so would make the world better. For something to genuinely belong to a person, he needs protection against requirements to give others the use of his belongings as well as protection against unwanted effects on his belongings.

I suggest that he needs protection against requirements that involve normative imposition. In normative imposition, the needs of another person intrude into the agent's sphere. The agent is required to ensure that some substantial fact about his resources holds for the sake of another. This involves giving the use of his body or resources to others. This infringes the authority that the agent should have over what is his. For an 
object to genuinely belong to a person, he must have prima facie protection against such imposition. ${ }^{26}$

Thus, for something to genuinely belong to a person, he needs prima facie normative protection against both causal imposition and normative imposition. This is just the protection provided by the Doctrine of Doing and Allowing. Thus, some version of the Doctrine of Doing and Allowing is required to recognise a person's authority over what belongs to him. ${ }^{27}$ Without some version of the Doctrine of Doing and Allowing, persons would not have the required privileged status with respect to the things that belong to them. In effect, nothing would genuinely belong to us. I think that the claim that nothing genuinely belongs to us is highly implausible. We have at least one clear case of a thing that genuinely belongs to a person: that person's body. ${ }^{28}$

\section{Exceptions, restrictions and limits}

The protection against imposition that I have described is prima facie rather than absolute. I can have enough authority over an object for it genuinely to belong to me without absolute protection against imposition. My car still belongs to me if I am required to use it to drive a person to the hospital if they have a heart attack in front of me even if doing so would lead to serious damage to the car. Our prima facie protection against imposition can be over-ridden by strong conflicting considerations. Nonetheless, my authority must have some significant normative bite. If it is too weak or too restricted, then we have mere tokenism rather than anything that could count as genuine belonging. ${ }^{29}$

This fits with the most plausible version of the Doctrine of Doing and Allowing. The most plausible version of the Doctrine of Doing and Allowing states that doing harm is significantly harder to justify than merely allowing harm. This requires significant - but not absolute - constraints against doing harm and significant - but not absolute - permissions to allow harm.

Nonetheless, any recognisable version of the Doctrine must have some force even in emergency situations. In the Boulder cases, Bob is permitted to allow lethal harm to Victor to save his own life but not permitted to do lethal harm to Victor to save his own life. I suggest that this pattern of constraints and permission is required for genuine belonging. If Bob is required to let his body or resources be used to save Victor's life even at the cost of Bob's own life, then that body and those resources do not genuinely belong to Bob. If Bob is permitted to lethally harm Victor's body to save his own life then Victor's body does not genuinely belong to Victor. If we only have special authority over what belongs to us in trivial cases, if this 
authority melts away when something important is at stake, then we have something more like lip service than genuine belonging. ${ }^{30}$

These observations enable me to respond to another objection to my account. Disaggregationists about ownership argue that we should not try to pick out a core set of rights that are essential to ownership. Instead, we should recognise ownership as a loose bundle of rights. In many cases, a person owns a resource even though some standard ownership rights are missing or restricted. We are required to let various government officials have access to our land; zoning restrictions may prevent the owner of a building from using it for a certain business. ${ }^{31}$ It might be thought that we should take a similar position with respect to the concept of belonging. This would cast doubt on my claim that the protection against imposition offered by the Doctrine of Doing and Allowing is necessary for anything to genuinely belong to a person.

We can reject the loose bundle theory of belonging while recognising that there are often exceptions to a person's authority over what belongs to him. The authority I have been discussing does not represent a disparate bundle of rights. There is a single unified idea behind it: for a resource to belong to a person is for that resource to be allocated to his use. I suggest that a combination of protection against causal imposition and protection against normative imposition is needed to reflect this idea.

For a resource to genuinely belong to a person, he must have prima facie protection against imposition. Perhaps certain impositions are permitted. My garden still belongs to me even if I am required to let the council dig up the garden to maintain public utilities. My ears still belong to me if others are permitted to speak without worrying about the tiny vibrations caused in my eardrums. However, when this is so, it must be for a good reason which is strong enough to over-ride or cancel the prima facie protection. Additionally, these exceptions must be strictly limited to avoid eroding the person's authority until we no longer count the resource as genuinely his. As above, such restrictions match the most plausible version of the Doctrine of Doing and Allowing, which gives significant but nonabsolute constraints and permissions. ${ }^{32}$

\section{Objections to my use of the notion of belonging}

In this section, I shall consider various objections to my use of the notion of belonging. First, I will look at the objection that I have merely pushed the problem of justifying the Doctrine of Doing and Allowing back a step. It is not enough to say that for something to genuinely belong to me requires protection against imposition. We need to explain why our bodies and other resources belong to us and do not belong*, a relationship that is like belonging but is neutral between doing and allowing. ${ }^{33}$ 
When something genuinely belongs to us we have normative protection against both causal imposition and normative imposition. Both types of protection are needed to properly recognise our relationship to our bodies. These two types of protection both limit and complement each other. My protection against adverse effects on my body is limited by, and provides the limit for, the freedom others have to do what they wish with their bodies. Belonging* will not be able to maintain this balance between freedom of use and protection from adverse effects. My interest in the state of my body suggests that it must be impermissible for others to do harm to my body without strong justification. By hypothesis, belonging* is neutral between doing and allowing. So if my body belongs* to me it must also be impermissible for others to allow harm to come to my body. But then it seems as if my authority reaches out, past my body, into the bodies of others. They are required to put their bodies at my use to prevent harm to my body. They do not have the freedom to use their bodies. If our bodies merely belonged* to us, either the need for freedom of use or the need for protection against harmful effects would not be adequately recognised.

It might be asked why the freedom to use our bodies is valuable enough to justify accepting a lesser amount of other goods including pleasure and other sorts of freedom. My body is the thing with which I do things. It has an intimate connection with my agency. Without freedom to use my body, my agency must be directed not towards my own goals and interests but towards the greater good. This may undermine my very identity as an agent. It surely undermines any genuine kind of belonging. If I do not have freedom to use my body for my own good, rather than the good of others, then this body is not genuinely mine. Additionally, while the version of belong*ing described above may seem to recognise my interest in the state of my body, it does so to a limited extent. Just as others are forbidden from allowing harm to me, I will be forbidden from allowing harm to them. I will be required to countenance harm to my body whenever this will prevent greater harm to the bodies of others. As Quinn argues, rather than belonging to me, my body 'seems rather to belong to the human community' 34

To argue that our bodies belong* to us rather than belonging to us, where belong*ing does not attempt to recognise freedom of use, is to stretch the notion of belonging beyond recognition. While I admit that the claim that our bodies belong to us in a normatively significant sense may be challenged, to have shown that the opponents of the Doctrine of Doing and Allowing are committed to denying this claim is a significant step forward.

Some may find the claim that a person's body belongs to him contentious. Claims about self-ownership are often criticised on the grounds that we do not have some of the standard rights of ownership over our bodies. For example, many deny that a person is permitted to sell his body. These 
worries do not undermine my claim about belonging. As noted earlier, belonging is a thinner and more basic notion than ownership. To say that a resource belongs to a person is to say that it is currently his in a way that gives him a privileged status over the current use of that resource. Our bodies do belong to us in this sense.

We may not have full ownership rights over our bodies partly because our bodies belong to us in a more fundamental way than any mere object. My relationship to my body is non-transferable - I cannot make it the case that someone else stands in this relationship to my body - and nondefeasible - while I stand in this relationship to my body, it belongs to me no matter what relationship others have to it. It is impossible to stop my body from belonging to me while I live. Rights to transfer my body do not make sense.

I can recognise the morally significant differences between the way in which our bodies and minds belong to us and the way in which other resources belong to us. My authority over my body and mind is much more important than my authority over other resources. The protection given against impositions on my body and mind is more stringent and more difficult to override than the protection given against impositions on other resources. The Doctrine of Doing and Allowing should reflect this, so the strength of the constraint against doing harm and permissions to allow harm depends on whether the imposition in question is on the person's body or on some less fundamental resource. Such a nuanced version of the Doctrine of Doing and Allowing is welcome, for it may explain the moral significance of the distinction between action and inaction described earlier. It is plausible that constraints on allowing harm through inaction impose on the agent's body, while constraints on actively allowing harm merely impose on external resources. If so, we can expect harmful inaction to be permissible when harmful action would not be.

Another objection to my use of the notion of belonging is based on a concern about scope. It might be thought that only persons can have belongings. Yet the doing/allowing distinction still seems to be morally significant even if the victim is not a person or even a sentient creature. Most people see destroying a rare and beautiful tree as harder to justify than merely allowing such a tree to be destroyed. This might seem to suggest that the Doctrine outruns the notion of belonging, so this notion cannot be used to explain the Doctrine.

In fact, our intuitions about doing and allowing harm to non-persons are in accord with my account. The destruction of the tree is a bad thing, so we have prima facie reason not to act in such a way that it occurs. When it comes to allowing the tree to be destroyed to avoid some personal cost, this prima facie reason is often defeated by the protection the agent has against normative imposition. Thus it may often be permissible to allow the tree to be destroyed rather than suffer a personal cost. The agent's 
protection against normative imposition does not speak against requiring him not to destroy the tree to avoid a personal cost. Thus the prima facie reason springing from the badness of the tree's destruction is unopposed. It is usually impermissible to destroy the tree even if this is the only way to avoid suffering some personal cost. So my account explains why doing harm to a non-person can be harder to justify than merely allowing harm to a non-person. My account also explains an important way in which doing harm to persons differs from doing harm to non-persons. It is impermissible to do harm to a person even if this is the only way to prevent several others suffering the same harm. This is not the case when it comes to harm to non-persons. It is permissible to destroy one rare tree to prevent several others being destroyed. This is exactly what my account predicts. A person has protection against being harmed as part of his authority over what belongs to him, so it is impermissible to harm him even if this results in the best overall outcome. In contrast, the impermissibility of harming the tree springs solely from the badness of the tree being harmed, so it is not impermissible to harm the tree when this results in the best outcome.

It has been suggested to me that this response leads to a deeper worry. The worry is that my response reveals that I have really put forward two separate arguments: one argument in favour of its being permissible to allow harm, based on the notion about normative imposition; and another argument in favour of its being impermissible to do harm, based on the point about causal imposition. The critic wonders whether these two arguments have as much in common as I suggest. The two types of imposition are very different, so different that it might seem to be misleading to use the same term to describe both.

I admit that there are significant differences between the two types of imposition. Causal imposition involves the behaviour of another intruding on the person, bringing about unwanted effects to what belongs to him. In contrast, normative imposition does not involve anything happening to the person or what belongs to him. Instead, the person is subject to a demand, a moral requirement to respond to the need of another. Nonetheless, I maintain that there is sufficient similarity between these two types of imposition to justify using the same term. Although nothing is done to what belongs to me when I am normatively imposed upon, normative imposition is still properly characterised as an intrusion of another into my sphere. The needs of another force their way into my daily life, restricting my freedom to use what belongs to me. I am forced, if I am to live up to my moral duties, to leave what I am doing and respond. This is different, but analogous to, cases of causal imposition, where what belongs to me is affected directly by another's behaviour without the need for me to act. Causal and normative imposition both involve another intruding into the person's sphere. ${ }^{35}$ 
Finally, it might be argued that my appeal to the notion of belonging is not wrong, but simply fails to get to the heart of the ethical issues. A full explanation will need to explain which things belong to us and why. Such an explanation will need to appeal to more fundamental ethical concepts. In the end, it might be thought, we must be looking for the set of rights and duties that make it possible for each of us to have a significant degree of autonomy, while simultaneously relating to each other in ways that exhibit mutual concern and respect. Would it be more fruitful to search directly for this set of rights?

The appeal to belonging plays a key role in the defence of the Doctrine of Doing and Allowing. An argument that appealed directly to, for example, autonomy would need to show how constraints against doing harm and permissions to allow harm are connected to autonomy. What aspect of autonomy is in question? Why must the constraints be built around the doing/allowing distinction? In showing that the protection provided by the Doctrine of Doing and Allowing is necessary for anything to belong to a person, even his body, my argument provides a vital bridge. Additionally, it is a virtue of my argument that it does not depend on any particular account of what belongs to us and why. Different accounts of belonging lead to different versions of the Doctrine of Doing and Allowing. Disagreements about whether a given case should be classified as a doing or an allowing often boil down to disagreement about to whom an object belongs. My account is compatible with any account of belonging such that there are some objects that genuinely belong to us, in a way that is characterised by the protection against imposition I have described. ${ }^{36}$

\section{The positivel negative distinction}

My analysis of the doing/allowing distinction - and thus my defence of the Doctrine of Doing and Allowing - appeals to the distinction between positive and negative facts. Yet many people have doubts about the coherence or moral relevance of this distinction. I will not endorse an analysis of the positive/negative distinction in this article. Instead, I will try to reassure readers that after analysis the positive/negative distinction will be shown to be suitable for the role it plays in my argument.

Jonathan Bennett offers one of the most promising accounts of the positive/negative distinction. Bennett's account is based on the idea that the positive/negative distinction is a distinction in how informative the relevant fact is. Positive facts tell us something fairly definite, pinning us down to a small set of alternatives. In contrast, negative propositions do not tell us very much about the world, only ruling out the relatively small set of alternatives corresponding to the positive proposition that has been negated. 
Unfortunately, it may not make sense to consider whether a fact is informative overall. Thus Bennett restricts his account. A positive fact about an agent's behaviour is informative about the agent's movements. So a fact about an agent's behaviour is positive if and only if most of the ways the agent could have moved would not have made that fact hold. A fact about an agent's behaviour is negative if and only if most of the ways the agent could have moved would have made the fact hold. We work out whether a proposition about an agent's behaviour is positive or negative by considering the agent's 'behaviour space': a square representing all the ways the agent could move his body at that time. Every point in the square represents an absolutely specific way of moving. So any proposition about how the agent moves will be represented by some subset of the behaviour space - all the specific ways he could have moved that would have made the proposition true. A proposition is positive if and only if the associated subset covers only a small proportion of the behaviour space.

As Bennett points out, this can be naturally extended to analyse the distinction between positive and negative facts about an object's position. ${ }^{37}$ Indeed, it gives us an analysis for a distinction between positive and negative facts about $\mathrm{X}$ whenever we can make sense of 'most ways that $\mathrm{X}$ could be.${ }^{38}$ When this is the case, a fact about $\mathrm{X}$ will be positive if and only if most ways that $X$ could be would not make the fact hold and negative if and only if most ways that $\mathrm{X}$ could be would make the fact hold.

Bennett's account offers reassurance that there is some way of making sense of the distinction between positive and negative facts. However, if his is the best analysis available, my account of the doing/allowing distinction faces a challenge. Bennett argues that on his analysis the distinction between positive and negative facts is 'obviously' without moral significance. ${ }^{39}$

I suggest that whether a fact is positive or negative on Bennett's analysis does matter morally. It matters whether a fact tells us that something specific is the case or simply rules some small set of alternatives out. Requirements to make a positive proposition about one's body or resources true - to ensure that something relatively specific about one's body or resources holds - undermine the agent's freedom to use what belongs to him. They put what belongs to him at the use of another. Such requirements should be seen as normative impositions. For something to genuinely belong to a person, he requires normative protection against such requirements. Whether the facts through which an agent is relevant to an upshot are positive or negative also affect whether his behaviour should be seen as a causal imposition. If the relevant fact is negative, then many different alternatives would have made the relevant proposition true. As far as the upshot's occurrence is concerned, it does not matter much exactly how things are. All that matters is that one particular alternative is ruled out. Absent other factors, this fact should not count as part of the 
sequence leading to the upshot. In contrast, if the relevant fact is positive, the upshot's occurrence will depend one of a small set of alternatives holding. This is a significant fact, a fact that is suitable to be part of the sequence leading to an upshot. We should see relevance through a complete sequence of such facts as a causal imposition, as one person's behaviour intruding into the other's sphere. Our authority over what belongs to us should protect us against such impositions. It should not protect us against others being relevant to effects on what belongs to us through negative facts about what belongs to them - for such protection would extend the owner's authority past what belongs to him into what belongs to others.

\section{A counter-example to the analysis}

Bob acquires a gun, set up, ready cocked, in a fixed position. When Victor stumbles into the sights of the gun, Bob pulls the trigger. The gun fires, the bullet hits Victor and Victor dies. Any account that does not hold that Bob does harm to Victor is unacceptably counterintuitive. However, as Jonathan Schaffer points out, in most guns, pulling the trigger is only relevant to the bullet firing through a negative fact. The sear keeps the spring coiled. Pulling the trigger disconnects the sear, allowing the spring to uncoil. This propels the striker onto the powder, producing the explosion which sends the bullet from the gun. ${ }^{40}$ The gun, and thus the sear, belongs to Bob. So the negative fact that the sear is no longer holding back the spring should be a mere condition for Victor's death - as should Bob's removal of the sear. My account seems to misclassify Bob's behaviour as merely allowing harm.

The answer to this puzzle lies in appreciating the complex role the sear plays in the sequence leading to Victor's death. Without the sear pushing back the spring, we would not have the pressure needed to drive the hammer forward and ignite the propellant. Without the sear, there would be no threat of death. The sear is not simply a barrier to harm. The sear is itself part of the sequence leading to harm. So Bob is not simply preventing one of his resources from preventing harm. He is making it the case that this resource does harm. ${ }^{41}$ This suggests that we need a slight amendment to both the analysis of the doing/allowing distinction and the account of imposition. We should say that a non-substantial fact about an agent's resources is relatively substantial if the resource in question is linked to the upshot in this way; i.e. if a fact about the resource is part of the sequence leading to harm.

This modification fits with natural thoughts about imposition. Acting in such a way that your resources impose on a person should count as causal imposition. Constraints against preventing your resources from protecting 
a person from a threat posed by those very resources should not count as a normative imposition. There is a natural and coherent way of amending the account of the doing/allowing distinction and the accounts of imposition that accommodates these problematic gun cases.

\section{Conclusion}

The above arguments give a conditional justification for the Doctrine of Doing and Allowing. If things do genuinely belong to us, then morality should incorporate some version of the Doctrine of Doing and Allowing. However, I think that the claim that nothing genuinely belongs to us is highly implausible. We have at least one clear case of a thing that genuinely belongs to a person: that person's body.

There is still work to be done. A fully satisfying theory must explain why our bodies belong to us, grounding this in a more general account of morality. However, substantial progress has been made. I have argued that some version of the Doctrine of Doing and Allowing is needed to recognise that our bodies genuinely belong to us. The opponent of this doctrine is committed to a highly implausible claim. ${ }^{42}$

Department of Philosophy

University of Southampton

\section{NOTES}

1 For prominent examples see Bennett, 1995; Tooley, 1983; and Rachels, 1975.

Quinn, 1989, p. 308.

3 Howard-Snyder, 2002, §5.

Quinn, 1989, p. 307. For criticism of this argument, see Strudler and Wasserman, 1995.

5 Howard-Snyder, 2002, §5.

See for example Narveson, 1985; Mack, 2005.

McMahan, 1998, p. 411.

Foot, 1984, p. 282. Elsewhere, I've argued that Foot's own account of the doing/ allowing distinction is incomplete as it stands, but that an account similar to that suggested in this article provides the most sympathetic formulation of her key idea. See Woollard, 2008. Here my focus is on defending the Doctrine of Doing and Allowing rather than interpreting Foot's work.

9 When an agent either does harm or allows harm, the harm depends in an appropriate way on some fact about the agent's conduct. I say that a fact is relevant to a harm if the harm depends upon the fact in the appropriate way. Cases of pre-emption teach us that the appropriate sort of dependence is not simple counterfactual dependence. Bob may have killed Victor even if some other person would have ensured Victor's death if Bob had behaved differently. If Bob is the one who pushes the boulder, Bob does harm to Victor. The literature on causation is full of examples of pre-emption and overdetermination. For a classic discussion see Lewis, 1986. 
${ }^{10}$ McMahan, 1993, p. 261.

${ }^{11}$ Ibid., p. 392. McMahan cites Jonathan Bennett as the source of this example. See Bennett, 1981, p. 91. The example is originally titled 'The Impoverished Village 3'. It is analogous to Shelley Kagan's Abdul case. See Kagan, 1989, p. 107.

${ }^{12}$ If the villagers have come to rely on the income, the agent may have a responsibility to give appropriate notice before discontinuing aid. He still counts as merely allowing harm.

${ }^{13}$ See Bennett, 1995, pp. 4-6. Bennett states that for an agent to count as harming the causal route must not depend on a series of unlikely coincidences or 'run wholly through someone's will' (p. 5). He notes that the emphasis on will is important, for an agent may still count as harming if the route runs through another's action. In Bennett's example, a servant innocently delivers poisoned food. The poisoner still counts as doing harm for, Bennett says, the chain runs through the servant's action but not his will. However, a further qualification is needed. We find it quite natural to say that Queen Elizabeth I killed Mary Queen of Scots, although she did not wield the axe. She issued an order, which a subordinate decided to obey. The sequence leading from Elizabeth's action to Mary's death runs wholly through another's will and yet Elizabeth is still classified as doing harm. I suggest that this is because the subordinate's will is not seen as sufficiently independent. His reason for killing Mary is that Elizabeth has ordered him to do so. I thank two anonymous referees, the first for pressing me to discuss the general issue, the second for noting the need for an amendment to deal with cases in which a subordinate obeys an order to harm.

${ }^{14}$ For the sake of simplicity, I have not discussed naturally occurring barriers or barriers provided by a third party. In 'resources belonging to the victim' I include previously unclaimed natural resources that the victim is obviously using and resources belonging to a third party that the provider intends the victim to use. In 'resources belonging to the agent', I include unclaimed natural resources or resources belonging to a third party that are not in use by the victim or intended by the provider for use by the victim. For comment on how this modified account fits with my defence of the Doctrine of Doing and Allowing see Endnote 28.

${ }^{15}$ Kamm, 1996, p. 24.

${ }^{16}$ Ibid., p. 25.

${ }^{17}$ Ibid., p. 25.

18 The use of the phrase 'as such' should be understood in the same way as we might say that blowing one's nose as such does not harm others. This claim leaves room for the possibility that some special features of a situation - additional to the features that make the behaviour count as a nose-blowing - may mean it causes harm. Similarly, I leave room for the possibility that some special features could make an allowing of harm an imposition.

${ }^{19}$ See Honoré, 1961 for a classic analysis of the legal implications of ownership.

${ }^{20}$ My concept of belonging has much in common with control ownership as described by John Christman (1994a, 1994b). Christman argues that ownership should be divided into two distinct rights packages: (1) control ownership which includes the right to use, the right to possess; the right to manage, and rights to alienate, destroy and modify; (2) income ownership which contains rights to transfer and gain income from goods (1994b, p. 231). However, belonging differs from control ownership in that it is a moral rather than a legal concept and, as argued above, a resource may belong to a person even if he does not have a full right to manage or rights to alienate, destroy and modify.

${ }^{21}$ Honoré, 1961, p. 113.

${ }^{22}$ Ibid., p. 116.

${ }^{23}$ Ibid., p. 113.

${ }^{24}$ Ibid.

${ }^{25}$ Honoré, 1961, p. 116. Kamm points this out in her criticism of Quinn. Kamm, 2007, p. 82 . 
${ }^{26}$ My argument that genuine belonging requires the protection against normative imposition provided by the Doctrine of Doing and Allowing has some common ground with an argument given by Seana Shriffin that agents must have options not to maximise the good (Shriffin, 1991). Without such options the agent lacks moral autonomy, where this is understood as the opportunity to exercise her capacity for choice without thereby having to choose between the moral and the immoral. Shriffin argues that moral constraints should be understood as comparable to other interferences with autonomy: 'Like other cases of objectionable interference, they deprive the agent of the opportunity to exercise her capacity for choice without thereby jeopardizing something else she has a right or reasonable expectation to enjoy' (p. 252). My argument also depends upon the claim that moral constraints can be seen as objectionable interference with an agent's freedom. However, my focus is much narrower than Shriffin's. Shriffin explicitly states that she intends only to defend the need for options without taking a stand on which set of options is needed (p. 254). I argue that we require the options provided by the Doctrine of Doing and Allowing. Additionally, where Shriffin appeals to general moral autonomy, I focus on the agent's freedom to (permissibly) use what belongs to him. My thanks to the referee who drew my attention to this common ground.

${ }^{27}$ By a 'version' of the Doctrine of Doing and Allowing, I mean the scheme of constraints and permissions that follows from a given account of what belongs to us.

${ }^{28}$ In Endnote 14, I note that my account of the doing/allowing distinction is slightly simplified in this article. My defence still stands under the more complex account. First, I suggest that it makes sense to see naturally occurring barriers and barriers provided by third parties as temporarily 'belonging to' either agent or victim under certain circumstances. Second, these more complex cases match up with protection of a person's say over what most clearly belongs to him. For example, removing a naturally occurring barrier will not causally impose on the victim, so will not be subject to the strong constraint against doing harm.

${ }^{29}$ Much more needs to be said about the restrictions on authority that are compatible with genuine belonging. I suggest that reflection on the limits of the required protection against normative imposition can be used to show: (1) that we are required to sacrifice a lot to save others from harm in immediately-present emergency situations, but that we are not required to make such large sacrifices to solve the ongoing problem of devastating poverty; (2) that we are required to make regular moderate contributions of time and money to aid programmes. Such requirements are compatible with belonging so long as the agent's body and resource remain, substantially enough, at his own use. As can be seen, I do not endorse the rightlibertarian argument that redistributive taxation is impermissible because incompatible with self-ownership (c.f. Nozick, 1974).

${ }^{30}$ Similar considerations suggest that, if our bodies are to genuinely belong to us, there must be significant but non-absolute constraints against doing harm and permissions to allow harm even when we must choose between one death and more than one death.

${ }^{31}$ See Grey, 1961/1980. For critical discussion see Munzer, 1990, pp. 31-36 and Christman, 1994a and b amongst others.

${ }^{32}$ I thank Kai Draper for pressing me on the speech case.

${ }^{33}$ This objection is based on Bennett's use of 'dual rights' to criticise Foot's defence of the Doctrine of Doing and Allowing. See Bennett, 1995, p. 81.

${ }^{34}$ Quinn, 1989, p. 308.

${ }^{35}$ As noted earlier (see Endnote 26), my argument depends on the view that moral requirements are comparable to other interferences with a person's freedom. This claim is ably defended by Seana Shriffin: 'Like other cases of objectionable interference, they deprive the agent of the opportunity to exercise her capacity for choice without thereby jeopardizing something else she has a right or reasonable expectation to enjoy' (Shriffin, 1991, p. 252). 
${ }^{36}$ I thank the anonymous referee who pressed me to explain how my account deals with harm to non-persons, and put forward the worry about the dissimilarity between the two types of imposition and the objection that the appeal to belonging fails to get to the heart of the ethical issues.

${ }^{37}$ Bennett, 1995, p. 98.

${ }^{38}$ We can make sense of 'most ways $\mathrm{X}$ could be' making a fact hold whenever $\mathrm{X}$ gives us an appropriate comparison class, such that we can compare the size of subsets of that comparison class. The comparison class for facts about the agent's behaviour is the behaviour space. I argue elsewhere that Bennett's own method for comparing the size of subsets of the behaviour space is inadequate, but that an adequate alternative can be provided. See Woollard, 2011.

${ }^{39}$ See Bennett, 1995, p. 102, pp. 139-142.

${ }^{40}$ Schaffer, 2000, p. 287.

${ }^{41}$ It does not matter that a non-substantial fact about the sear is also relevant to the sequence. The fact that the sear pushes back the spring is not relevant solely through this non-substantial fact. (See definition of 'solely relevant through' on p. 8.)

${ }^{42}$ I thank Brad Hooker, John Cottingham, James Lenman, Frances Kamm, Kai Draper, several anonymous referees, and audiences at Reading, Sheffield, Oxford, and the Rocky Mountains Ethical Congress 2009 for helpful comments. I also thank the AHRC and the Mind Association for an AHRC Doctoral Award and a Mind Association Early Career Research Fellowship, both of which provided financial support for parts of the period during which this research was undertaken.

\section{REFERENCES}

Bennett, J. (1981). 'Morality and Consequences', in S. McMurrin (ed.) The Tanner Lectures on Human Values. Salt Lake City, UT: University of Utah Press.

Bennett, J. (1995). The Act Itself. Oxford: Oxford University Press.

Christman, J. (1994a). 'Distributive Justice and the Complex Structure of Ownership', Philosophy and Public Affairs 23, pp. 225-250.

Christman, J. (1994b). The Myth of Property: Toward an Egalitarian Theory of Ownership. New York: Oxford University Press.

Foot, P. (1984). 'Killing and Letting Die', in J. Garfield and P. Hennessey (eds) Abortion and Legal Perspectives. Amherst, MA: University of Massachusetts Press. Reprinted in B. Steinbock and A. Norcross (eds) Killing and Letting Die. New York: Fordham University Press, pp. 266-267. Page references to reprint.

Grey, T. C. (1961) [1980]. 'The Disintegration of Property', in J. R. Pennock and J. W. Chapman (eds) Nomos XXII: Property. New York: New York University Press, pp. 69-71.

Honoré, A. M. (1961). 'Ownership', in A. G. Guest (ed.) Oxford Essays in Jurisprudence. Oxford: Oxford University Press, pp. 107-147.

Howard-Snyder, F. (2002). 'Doing vs. Allowing Harm', in E. N. Zalta (ed.) The Stanford Encyclopedia of Philosophy (Summer 2002 Edition), Online at: http://plato.stanford.edu/ archives/sum2002/entries/doing-allowing/

Lewis, D. (1986). 'Postscripts to "Causation", in his Philosophical Papers, Volume II. Oxford: Oxford University Press.

Kagan, S. (1989). The Limits of Morality. Oxford: Oxford University Press.

Kamm, F. (1996). Morality, Mortality. New York: Oxford University Press.

Kamm, F. (2007). Intricate Ethics. New York: Oxford University Press.

Pacific Philosophical Quarterly (C) 2013 John Wiley \& Sons Ltd \& University of Southern California. 
Mack, E. ((2005). 'Prerogatives, Restrictions, and Rights', Social Philosophy and Policy 22, pp. 357-393.

McMahan, J. (1993). 'Killing, Letting Die, and Withdrawing Aid', Ethics 103, pp. 250-279.

McMahan, J. (1998). 'A Challenge to Common Sense Morality', Ethics 108, pp. 394-418.

Munzer, S. (1990). A Theory of Property. Cambridge: Cambridge University Press.

Narveson, J. (1985). 'Positive/Negative: Why Bother?', in E. Mack (ed.) Positive and Negative Duties. Tulane Studies in Philosophy Vol. 33. New Orleans, LA: Tulane University, pp. $51-66$.

Nozick, R. (1974). Anarchy, State, and Utopia. New York: Basic Books.

Quinn, W. S. (1989). 'Actions, Intentions, and Consequences: The Doctrine of Doing and Allowing', The Philosophical Review 98, pp. 287-312.

Rachels, J. (1975). 'Active and Passive Euthanasia', New England Journal of Medicine 292, pp. $78-80$.

Schaffer, J. (2000). 'Causation by Disconnection', Philosophy of Science 67, pp. 285-300.

Shriffin, S. (1991). 'Moral Autonomy and Agent-Centred Options', Analysis 51, pp. 244-254.

Strudler, A. and Wasserman, D. (1995). 'The First Dogma of Deontology: The Doctrine of Doing and Allowing and the Notion of a Say', Philosophical Studies 80, pp. 51-67.

Tooley, M. (1983). Abortion and Infanticide. Oxford: Clarendon.

Woollard, F. (2008). 'Doing and Allowing, Threats and Sequences', Pacific Philosophical Quarterly 89, pp. 261-277.

Woollard, F. (2011). 'Most Ways I Could Move: Bennett's Act/ Omission Distinction and the Behaviour Space', Mind 120, pp. 155-182. 